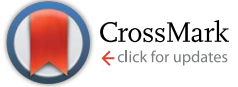

Cite this: J. Mater. Chem. A, 2016, 4 , 14614

Received 6th June 2016

Accepted 23rd August 2016

DOI: $10.1039 / c 6 t a 04737 h$

www.rsc.org/MaterialsA

\title{
Carbon dots with tunable concentrations of trapped anti-oxidant as an efficient metal-free catalyst for electrochemical water oxidation $\uparrow$
}

\begin{abstract}
Abheek Datta, Sutanu Kapri and Sayan Bhattacharyya*
The challenging water oxidation reaction to generate molecular oxygen requires low-cost efficient catalysts for its application in renewable energy technologies. Carbon dot ( $\mathrm{C}$-dot) catalysts synthesized by microwave irradiation can trap an anti-oxidant, 5-hydroxymethyl-2-furaldehyde (5-HMF) inside the carbon framework. The $\mathrm{C}$-dot with the highest concentration of 5-HMF acts as a stable metal-free oxygen evolution reaction (OER) catalyst which operates at a decently low $0.21( \pm 0.03) \mathrm{V}$ overpotential and can generate current density up to $33.6( \pm 2.3) \mathrm{mA} \mathrm{cm}{ }^{-2}$. With increased microwave reaction time, the concentration of $5-\mathrm{HMF}$ inside the $\mathrm{C}$-dots decreases at the cost of different furan derivatives which decreases the OER activity. The 5-HMF molecules in close vicinity to the catalytically active sites containing $\mathrm{C}=\mathrm{O}$ groups can extract the $\cdot \mathrm{OH} /{ }^{\circ} \mathrm{OOH}$ radicals and can increase the in situ $\mathrm{H}_{2} \mathrm{O}$ concentration to facilitate the forward reaction of $\mathrm{O}_{2}$ evolution. During continuous electrolysis beyond $10 \mathrm{~min}, 5$-HMF gets converted to 2,5-diformylfuran entities, which increases the catalytically active sites and thereby maintains the OER activity of the $\mathrm{C}$-dots for at least $4 \mathrm{~h}$. The ability of microwave irradiated sucrose derived $\mathrm{C}$-dots to electro-oxidize water is generalized with $\mathrm{C}$-dots and graphene dots (G-dots) prepared from different precursors.
\end{abstract}

\section{Introduction}

The impending energy crisis in today's world is driving the search for mature, clean and renewable energy in the form of fuels and water oxidation to molecular oxygen has attracted immense attention in this respect. ${ }^{1-3}$ However, water electrolysis is thermodynamically unfavorable since the standard reduction potential $E_{\mathrm{O}_{2} / \mathrm{H}_{2} \mathrm{O}}^{\mathrm{O}}$ per electron transferred is $1.23 \mathrm{~V}$ versus reversible hydrogen electrode (RHE) and the associated free energy $(\Delta G)$ is $237.2 \mathrm{~kJ} \mathrm{~mol}^{-1}$. $^{4,5}$ The OER in the natural enzyme photosystem II is catalyzed by cubane-like $\mathrm{Mn}_{4} \mathrm{CaO}_{x}$ active sites, in a physiological $\mathrm{pH}$ environment with a moderate overpotential $(\eta)$ of $0.3-0.4 V .^{5,6}$ Developing a nature mimicking, stable OER catalyst for artificial photosynthesis is a formidable challenge and a body of recent work is available in the search for efficient, robust and inexpensive electro-catalysts. ${ }^{2,7,8}$ A majority of the OER catalysts known to date suffer from limitations such as low current density $(J)$ and overpotential of several hundred millivolts. Although precious metals such as Ru and Ir metals are known to demonstrate reliable OER activities, ${ }^{9}$ the

Department of Chemical Sciences and Centre for Advanced Functional Materials, Indian Institute of Science Education and Research (IISER) Kolkata, Mohanpur 741246, India. E-mail: sayanb@iiserkol.ac.in; Fax: +91-33-25873020; Tel: +919051167666

$\dagger$ Electronic supplementary information (ESI) available. See DOI: $10.1039 / \mathrm{c} 6 \mathrm{ta} 04737 \mathrm{~h}$ nanoparticles of these metals are prone to corrosion at applied OER potentials and under non-physiological $\mathrm{pH}$ conditions. Moreover, $\mathrm{IrO}_{x}, \mathrm{RuO}_{x}$ and earth abundant transition metal oxides are some of the well-known OER catalysts which work at 0.32-0.5 V. ${ }^{\mathbf{1 0} 11}$ In addition, homogeneous molecular complexes based on $\mathrm{Ru}$, Ir and $3 \mathrm{~d}$ transition metals have demonstrated decent OER activities. ${ }^{2,5,12-14}$ All the metal based catalysts have issues such as scarcity, toxic nature, difficulties in disposal and secondary pollution. Bioinspired catalysts based on the naturally occurring metalloenzymes have also gained attention. ${ }^{15}$ In recent years, metal-free heterogeneous catalysts have emerged as the new alternatives to the metal based catalysts. ${ }^{16}$ The development of an earth abundant, metal-free, easy to synthesize and stable OER catalyst that can operate at low $\eta$ close to $\mathrm{pH}$ 7 remains a fundamental challenge. ${ }^{17}$

The applications of carbon containing nanomaterials are abundant in photoelectrochemical water splitting, ${ }^{18,19}$ photocatalysis, ${ }^{20}$ fuel cells, ${ }^{21,22}$ solar cells, ${ }^{23}$ spintronic devices, ${ }^{24,25}$ drug delivery, ${ }^{\mathbf{2 6 - 2 8}}$ and greener approaches to materials design. ${ }^{29}$ Carbon based catalysts have also been used for oxygen reduction and other miscellaneous reactions. ${ }^{\mathbf{1 6 0 - 3 0} 33}$ However, reports on metal-free OER electro-catalysts are rather scarce except the OER activities shown by N-doped 30-40 nm carbon nanoparticles, ${ }^{7}$ g- $\mathrm{C}_{3} \mathrm{~N}_{4}$ coupled $\mathrm{N}$-doped graphene, ${ }^{8}$ and surface modified carbon nanotubes. ${ }^{3}$ Also, most of the carbon catalysts require heteroatom modification especially doping with nitrogen atoms. ${ }^{7}$ The OER involves a large variety of possible 
pathways and irrespective of the absence of an unambiguous mechanism, it is argued that in alkaline medium, the overall OER activity according to the half-cell reaction: $4 \mathrm{OH}^{-} \rightarrow \mathrm{O}_{2}+$ $2 \mathrm{H}_{2} \mathrm{O}+4 \mathrm{e}^{-}$is determined by the rates of adsorption and desorption of hydroxyl radicals on the catalyst surface. ${ }^{34}$ In this regard, encasing a ${ }^{\circ} \mathrm{OH}$ scavenger inside a metal-free nanoparticle such as C-dots is highly lucrative to test the OER activity. On the other hand, the multifaceted C-dots containing encapsulated aromatic molecules within a carbon scaffold are usually employed in optoelectronics, bio-imaging and sensing applications (ESI Table S1 $\dagger$ ), ${ }^{35}$ but were rarely used as catalysts, ${ }^{36-39}$ and particularly no report is available on their use as OER catalysts. We show that the water-dispersible pristine C-dots are excellent OER catalysts providing one of the highest $J$ and lowest $\eta$ to date. Although microwave irradiation is known to be a successful technique for synthesizing C-dots from various precursors, ${ }^{\mathbf{4 0 - 4 4}}$ the novelty of our approach lies in microwaving a precursor mixture of carbohydrate (sucrose), weak acid (oxalic acid) and a binder (polyvinylpyrrolidone, PVP) for a limited duration to arrest the anti-oxidant inside the C-dots. The catalytic activity of the synthesized C-dots depends on the microwave irradiation time. The radical scavenger antioxidant 5-HMF encased C-dots C5, C10 and C15 were prepared by altering the microwave reaction time as 5, 10 and $15 \mathrm{~min}$, respectively. Increasing the microwave reaction time to $20 \mathrm{~min}$ (C20), $25 \mathrm{~min}$ (C25) and $30 \mathrm{~min}$ (C30) cannot retain 5-HMF which subsequently undergoes complete polymerization into aromatic compounds with $\mathrm{C}=\mathrm{O}$ linkages. C-dots were also synthesized from other precursors such as citric acid and ethylenediamine (C-A), sucrose, oxalic acid and cetyl trimethyl ammonium bromide (CTAB) with a microwave time of 5 and 10 min (C-B and $\mathrm{C}-\mathrm{C}$ ), glucose and $\mathrm{NaOH}$ in the presence and absence of PVP (C-D and C-E). The G-dots G5 and G10 were synthesized from citric acid and ethanolamine for 5 and $10 \mathrm{~min}$, respectively.

\section{Experimental}

\subsection{Materials}

Sucrose, glucose (pure grade, Merck India), citric acid (Sigma Aldrich, ACS reagent, $>99.5 \%$ ), oxalic acid dehydrate (Purified, Merck India), ethylenediamine (synthesis grade, Merck India), ethanolamine (Sigma Aldrich, $>99.5 \%$ ), potassium hydroxide and sodium hydroxide pellets (EMPLURA, Merck India), PVP (Loba Chemie, mol. wt. 40 000), CTAB (Sigma Aldrich, 98\%), 5-HMF (Alfa Aesar, 97\%) and Nafion perfluorinated resin solution (5 wt\%, Sigma Aldrich) were used without further purification.

\subsection{Synthesis of C-dots and G-dots}

To synthesize the C-dots (C5 to C30, C-A to C-E) microwave reactions were performed in a Sineo MASII-1000W commercial microwave oven, with a well-equipped refluxing system under constant stirring at $900 \mathrm{~W}$. The microwave heating was constantly monitored with an automated on/off program to avoid the risk of overheating. G5 and G10 were synthesized with an Anton Paar Monowave 300 microwave reactor, where the reactions can be controlled up to 30 bar and $300{ }^{\circ} \mathrm{C}$.

2.2.1 Synthesis of C-dots with differently trapped 5-HMF at increasing microwave reaction time (C5-C30). $0.005 \mathrm{~g}$ of PVP was added to a mixture of $10 \mathrm{~mL}$ of $0.5 \mathrm{M}$ sucrose and $5 \mathrm{~mL}$ of $0.5 \mathrm{M}$ oxalic acid aqueous solutions, and stirred for $10 \mathrm{~min}$ to obtain a homogeneous mixture. This solution was subjected to microwave irradiation at $100{ }^{\circ} \mathrm{C}$ under constant stirring. Reactions assisted by microwave irradiation were performed for 5 , 10, 15, 20, 25, and $30 \mathrm{~min}$ to obtain C5, C10, C15, C20, C25 and C30, respectively. Within 2 min of microwave irradiation, the color of the solution started changing from transparent to yellow. The colloidal solution of C5 was light brown which changed to blackish brown for C30.

2.2.2 Synthesis of C-dots from citric acid (C-A). C-A was synthesized as per a previous report, ${ }^{45}$ with slight modifications. $0.6 \mathrm{~g}$ of citric acid was dissolved in $15 \mathrm{~mL}$ of double-distilled water and then $1 \mathrm{~mL}$ of ethylenediamine was added to it. The final solution was exposed to microwave irradiation for $3 \mathrm{~min}$ to obtain a deep yellow suspension of C-A.

2.2.3 Synthesis of C-dots from sucrose with CTAB as the surfactant (C-B and C-C). This synthesis method is similar to the synthesis of C5-C30, except that PVP was replaced by $0.005 \mathrm{~g}$ CTAB. Reactions were carried out for 5 and 10 min to obtain brown C-B and blackish brown C-C colloids, respectively.

2.2.4 Synthesis of C-dots from glucose, with and without PVP (C-D and C-E). Synthesis of C-D and C-E was performed following a previously published report, ${ }^{46}$ albeit little modification. Firstly, $10 \mathrm{~mL}$ of $0.5 \mathrm{M}$ aqueous solution of glucose was mixed with $3 \mathrm{~mL}$ of $0.5 \mathrm{M}$ aqueous solution of $\mathrm{NaOH}$ and stirred constantly for $15 \mathrm{~min}$. The resultant solution was divided into two parts. $0.0025 \mathrm{~g}$ PVP was added to one half and microwave irradiated at $80{ }^{\circ} \mathrm{C}$ for $1 \mathrm{~min}$ to obtain a deep yellow C-D solution. The second half was sonicated whereby the light yellow color of the solution appeared after $45 \mathrm{~min}$, which changed to blackish brown after $2 \mathrm{~h}$ to obtain C-E.

2.2.5 Synthesis of G-dots from citric acid (G5 and G10). Synthesis of G5 and G10 was performed following a previous report with slight modifications. ${ }^{47}$ Citric acid and ethanolamine was mixed in a molar ratio of $1: 3$ and the solution was treated by microwave irradiation at $180^{\circ} \mathrm{C} .5$ and $10 \mathrm{~min}$ reactions gave greenish-yellow G5 and yellow G10 colloidal solutions.

\subsection{Separation and purification of C-dots and G-dots}

The uniform sized particles were separated and the samples were purified to remove the impurities and by-products. The crude colloidal suspensions were half-diluted with a $2: 1$ ethanol water mixture and centrifuged for $15 \mathrm{~min}$ at $13000 \mathrm{rpm}$ followed by collection of a clear supernatant. The whole exercise was repeated 3 times for each sample. For purification, the dispersions were introduced on a Fisher scientific dialysis tubing membrane (with a molecular weight cut-off of $3500 \mathrm{Da}$ ) and extensively dialyzed against de-ionized water for $36 \mathrm{~h}$. The as-received suspensions were solidified using a rotary evaporator. All the samples were kept under high vacuum to remove the moisture. 


\subsection{Characterization methods}

The ICP-MS measurements were performed with a Thermo Scientific X-series using Plasma lab software. TEM images were recorded using a JEOL JEM $2100 \mathrm{HR}$ model using a $200 \mathrm{kV}$ electron source. UV-visible absorption spectra were collected using a JASCO V-670 spectrophotometer. PL spectra were measured with a Horiba ScientificFluoromax-4 spectrofluorometer using a Xe lamp as the excitation source and excitation at $309 \mathrm{~nm}$. LC-MS studies were performed with an Agilent Q-TOF LC-MS 6520. ${ }^{1} \mathrm{H}$ NMR and ${ }^{13} \mathrm{C}$ NMR spectra were recorded on a JEOL ECS $400 \mathrm{MHz}$ spectrometer and on a Bruker Avance III $500 \mathrm{MHz}$ spectrometer. Chemical shifts $(\delta)$ downfield from the reference standard were assigned positive values. FTIR studies were performed with a Perkin Elmer spectrum RX1 with $\mathrm{KBr}$ pellets. $\mathrm{pH}$ of the solutions was measured using a standard pH meter (pH 510, Eutech Instruments). Electron paramagnetic resonance (EPR) measurements were performed with a Bruker A-300 instrument. The amount of evolved oxygen was measured using a Fischer Scientific dissolved oxygen meter. The amount of dissolved oxygen before and after one cycle was obtained from the difference between the two readings. The impedance measurements were carried out using a CHI Electrochemical workstation. The plots were analyzed with inbuilt software in the electrochemical workstation.

\subsection{Electrochemical measurements}

The electrocatalytic performance of the C-dots was measured with a conventional three electrode cell in a CHI604D electrochemical workstation. The working electrode was designed as follows: $1 \mathrm{mg}$ of dried C-dot was dispersed in a mixed solution containing $250 \mu \mathrm{L}$ distilled water, $250 \mu \mathrm{L}$ of ethanol and $25 \mu \mathrm{L}$ of $5 \%$ aqueous Nafion solution. $5 \mu \mathrm{L}$ of the resulting suspension was carefully drop cast onto the surface of the GC disk followed by drying at $25{ }^{\circ} \mathrm{C}$ for $0.5 \mathrm{~h}$. The scanning rate was maintained constant at $100 \mathrm{mV} \mathrm{s}^{-1}$. Since the catalyst shows a near steady state behavior at the electrode surface over $4 \mathrm{~h}$, the scan rate was not lowered according to a generic protocol. ${ }^{10}$

\section{Results and discussion}

\subsection{Characterization of the C-dots and G-dots}

The OER-active C-dots and G-dots were found to be "pure" by inductively coupled plasma - mass spectroscopy (ICP-MS) and all metal impurities were at the ppb level (Table S2 $\dagger$ ). X-ray diffractograms (XRD) with a lone (002) broad reflection of $\mathrm{sp}^{2}$ hybridized carbon show the primarily amorphous nature of the C-dots (Fig. S1 $\dagger$ ). The broadening of the XRD peaks from $\mathrm{C} 10$ to C30 is due to the increase in the diameter of the C-dots. All the C-dots show optical absorption in the UV region with $\pi-\pi^{*}$ and $\mathrm{n}-\pi^{*}$ transitions of the $\mathrm{C}=\mathrm{C}$ and $\mathrm{C}=\mathrm{O}$ bonds, respectively (Fig. S2 $\dagger$ ). The photoluminescence emission is dependent on the excitation wavelength (Fig. S3†), a property attributed to differently sized C-dots and various surface emissive traps. ${ }^{48}$ The evidence of dominant surface trap states which can serve as catalytically active sites was obtained from the extremely low fluorescence quantum yield (QY) of the samples (Fig. S4†). ${ }^{35,48}$
QY shows a steady increase from 1.3 for C5 to 2.6 for C30, varies between 1.6 and 5.3 for C-A to C-E and is highest for the G-dots, 15.1 for G5 and 18.5 for G10.

3.1.1 Evidence of trapped 5-HMF inside the C-dots. The microwave synthesis time was varied in order to alter the nature and concentration of the encased intermediates inside the C-dots which show a marked influence on the OER results. It is well known that the carbohydrate precursors, glucose and sucrose can initially undergo hydrolysis, dehydration and decomposition in the presence of weak organic acids such as oxalic acid to form furfural aldehydes, ketones and several organic acids, which after continued processing transform themselves into soluble polymerized aromatic products through condensation and cycloaddition reactions (Fig. S5 $\dagger^{4} \cdot{ }^{49,50}$ In the first step, sucrose undergoes acid hydrolysis in the presence of oxalic acid and forms glucose and fructose. Thereafter glucose transforms to the fructose molecule via a ring opening-closing step. Finally, fructose molecules undergo acid catalyzed dehydration to form 5-HMF molecules. Short microwave irradiation up to 15 min could trap 5-HMF in the C-dots, C5-C15 whereas increased microwave time for C20-C30 transforms 5-HMF into soluble polymerized aromatic products with $\mathrm{C}=\mathrm{O}$ linkages. $\mathrm{PVP}$ plays the role of a surfactant to stabilize the C-dots by encapsulating 5-HMF and other intermediates present due to incomplete carbonization, within an elemental carbon scaffold. ${ }^{51}$ In fact, 5-HMF was observed to form within $2.5 \mathrm{~min}$ of the microwave reaction between sucrose, oxalic acid and PVP, as shown by ${ }^{13} \mathrm{C}$ NMR spectroscopy (Fig. S6†). ${ }^{13} \mathrm{C}$ NMR of a commercial 5-HMF sample confirms this peak (Fig. S7†). $2.5 \mathrm{~min}$ is however not enough to encapsulate the 5-HMF molecules within a $\mathrm{sp}^{2}$ hybridized carbon scaffold, and because of the water-soluble nature of 5-HMF, the yield of this sample is pretty low, not enough for OER experiments.

The ${ }^{13} \mathrm{C}$ NMR spectra in Fig. 1a-f show the descending concentration of 5-HMF from C5 to C30. A single peak at 177.9 ppm characteristic of $\mathrm{C}_{1}$ in 5-HMF (Fig. $1 \mathrm{~g}$ ) is observed in C5 and $\mathrm{C} 10,{ }^{52}$ which is shifted to 178.6 for $\mathrm{C} 15$ as a result of increased carbohydrate decomposition. ${ }^{53,54}$ In C20 and C25, the signals at 162.9-182.9 $\mathrm{ppm}$ are due to the furan derivative intermediates formed by decomposition of 5-HMF. In fact, 160200 ppm peaks in $\mathrm{C} 20-\mathrm{C} 30$ can correlate with $\mathrm{C}=\mathrm{O}$ groups of these furan derivatives. Likewise, the population of aromatic $\mathrm{sp}^{2}$ carbon at 100-120 ppm starts increasing from C5 up to C30. The final condensation to polyaromatic rings is evident from the 120-140 ppm signals in C30. For C5-C30, multiple peaks in the $20-80 \mathrm{ppm}$ region correspond to $\mathrm{sp}^{3}$ hybridized carbon and the $\mathrm{C}-\mathrm{OH}$ groups such as $\mathrm{C}_{6}$ in 5-HMF. The 80-100 ppm signals are from the carbon attached to ether linkages in unreacted sucrose or its byproduct glucose trapped inside the C-dots. ${ }^{53}$

Liquid chromatography-mass spectroscopy (LC-MS) studies also support the trapping of 5-HMF in the C-dots. LC-MS spectra of C5, C10 and C15 show the presence of a prominent peak at $\mathrm{m} / z 127.4$ which confirms the presence of 5 -HMF (Fig. S8 $\dagger$ ). ${ }^{55}$ This peak is absent in $\mathrm{C} 20$ which indicates the absence of 5-HMF due to complete degradation to the furan derivatives with increased microwave time. Moreover, 5-HMF could be 

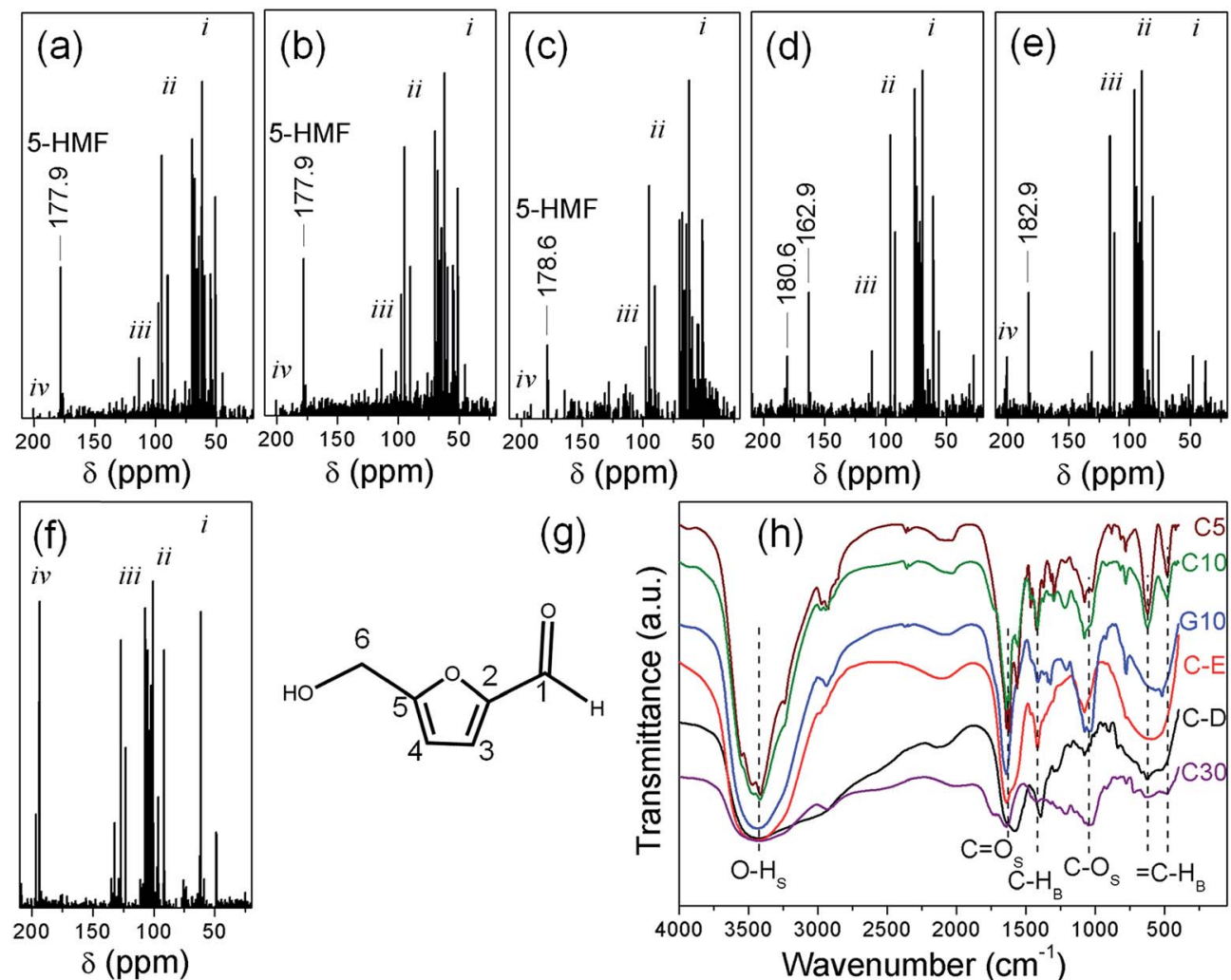

(g)
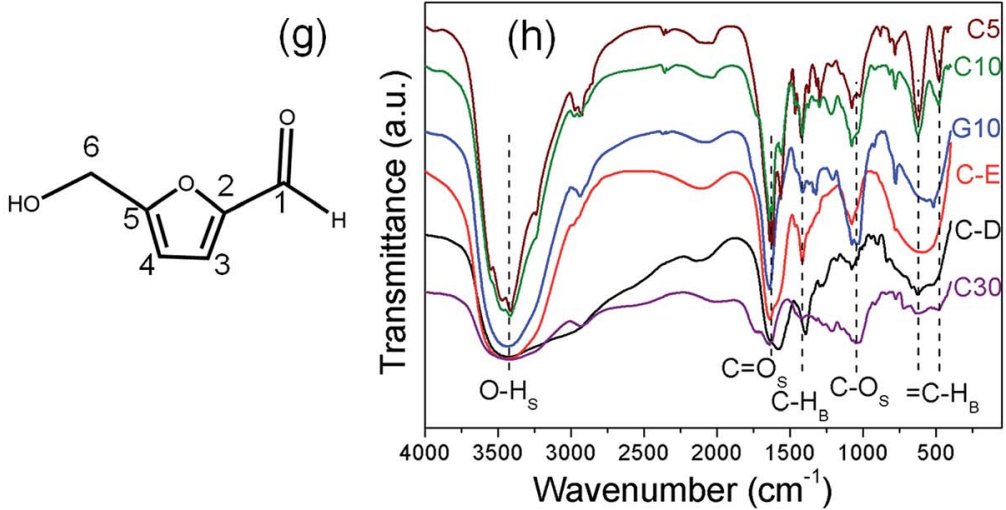

Fig. $1{ }^{13} \mathrm{C}$ NMR spectra of (a) C5, (b) $\mathrm{C} 10$, (c) C15, (d) C20, (e) C25, and (f) C30. (i) $\mathrm{sp}^{3}$ hybridized carbon and the $\mathrm{C}-\mathrm{OH}$ groups, (ii) carbon attached to ether linkages in leftover carbohydrates, (iii) aromatic $\mathrm{sp}^{2}$ carbon, and (iv) $\mathrm{C}=\mathrm{O}$ groups of furan derivatives. (g) Structure of 5 - $\mathrm{HMF}$. (h) FT-IR spectra of different $\mathrm{C}$-dots where subscripts $\mathrm{s}$ and $\mathrm{b}$ correspond to stretching and bending vibrations, respectively.

quantified by LC-MS analysis and the abundance of 5-HMF in C5, C10 and C15 is 93, 89 and 9\%, respectively.

The C-dots prepared from other precursors and surfactants fail to meet the reaction conditions required for the formation of 5-HMF (Fig. S5 $\dagger$ ). For example, for the formation of C-A, citric acid was used as the carbon precursor instead of sucrose. In the case of C-B and C-C, CTAB was used as the surfactant instead of PVP and could not trap the 5-HMF molecules. C-D and C-E were formed by basic hydrolysis of glucose instead of acid hydrolysis. G5 and G10 were prepared from citric acid instead of sucrose. The ${ }^{13} \mathrm{C}$ NMR spectra of C-A to C-E (Fig. S9†) likewise show the absence of the 5-HMF signal and the presence of $\mathrm{sp}^{3}$ hybridized carbon, $\mathrm{C}-\mathrm{OH}$ groups and ether linkages in leftover sucrose/ glucose.

Anti-oxidants are presumably unstable and soluble in water. Since all the samples post-microwave irradiation were dialyzed against de-ionized water for $36 \mathrm{~h}$, the left-over 5-HMF is not a physical mixture with the C-dots, rather the molecules are loaded inside the $\mathrm{C}$-dots. The stability of the anti-oxidant is thus enhanced by its impregnation inside the C-dots, beneficial to long term stability during electrocatalysis experiments. Moreover, the trapping of 5-HMF within a scaffold helps preventing them getting soluble in water medium which further benefits the OER activity of the C-dots by increasing the reaction kinetics through free-radical scavenging. ${ }^{56}$ Representative Fourier transform infrared (FT-IR) spectra in Fig. 1h show the carbonyl bands corresponding to either the carboxylic acid attached to the C-dot surface and/or ketonic $\mathrm{C}=\mathrm{O}$ groups of the furan derivatives which have been demonstrated earlier to alter the electronic distribution of the adjacent carbon atoms assisting the adsorption of OER intermediates. ${ }^{3}$ All the indexed functional groups were observed in $\mathrm{C} 5-\mathrm{C} 15$, and their origin is likely due to the 5-HMF molecules (Fig. 1g) trapped in the C-dots along with the furan molecules. In addition, the topological defects can promote the formation of charged sites through the formation of localized orbitals favourable for the adsorption of intermediates. $^{57}$

\subsection{Electrochemical activities of the C-dots and G-dots}

3.2.1 OER activity of the "champion" C-dot (C5) with the highest concentration of 5-HMF. The OER activities were evaluated in $1 \mathrm{M} \mathrm{KOH}$ using a three electrode cell assembly consisting of $\mathrm{Pt}$ wire as the counter electrode, $\mathrm{Ag} / \mathrm{AgCl}(3 \mathrm{M} \mathrm{KCl})$ as the reference electrode and a glassy carbon (GC) disk of $3 \mathrm{~mm}$ diameter coated with the C-dots as the working electrode. To exclude the influence of different reference electrodes, internal solutions e.g. $\mathrm{KCl}$ and $\mathrm{pH}$, the measured potential values were normalized with respect to a RHE. The data are reported after correcting the capacitive current for all the C-dots (Fig. S10 $\dagger$ ). The 1.7(1) nm diameter "champion" C-dot (C5) demonstrates a high current density of $33.6( \pm 2.3) \mathrm{mA} \mathrm{cm}^{-2}$ at pH 14 (Table 1) and a low overpotential of $0.21( \pm 0.03) \mathrm{V}$ at $10 \mathrm{~mA} \mathrm{~cm}^{-2}$ (Fig. 2a). The next lowest reported water oxidation overpotential was 
Table 1 OER-activity parameters

\begin{tabular}{|c|c|c|c|c|c|}
\hline Catalyst & $J\left(\mathrm{~mA} \mathrm{~cm}^{-2}\right)$ & $\eta @ 10 \mathrm{~mA} \mathrm{~cm} \mathrm{~cm}^{-2}(\mathrm{~V})$ & Tafel slope $\left(\mathrm{mV} \operatorname{dec}^{-1}\right)$ & $\operatorname{ECSA}\left(\mathrm{cm}^{2}\right)$ & Reference \\
\hline C5 & $33.6( \pm 2.3)$ & $0.21( \pm 0.03)$ & $68( \pm 4)$ & $17.5( \pm 2)$ & This work \\
\hline C10 & $29.2( \pm 1.5)$ & $0.36( \pm 0.06)$ & $90( \pm 8)$ & $12.8( \pm 2)$ & This work \\
\hline $\mathrm{C} 20$ & $18.9( \pm 1.6)$ & $0.4( \pm 0.08)$ & $112( \pm 2)$ & $10.7( \pm 0.9)$ & This work \\
\hline $\mathrm{C} 25$ & $17.6( \pm 2.1)$ & $0.41( \pm 0.02)$ & $104( \pm 3)$ & $8.96( \pm 0.9)$ & This work \\
\hline C30 & $16.3( \pm 1.4)$ & $0.43( \pm 0.05)$ & $124( \pm 8)$ & $8.2( \pm 0.6)$ & This work \\
\hline $\mathrm{C}-\mathrm{C}$ & $19.05( \pm 0.9)$ & $0.39( \pm 0.04)$ & $97( \pm 5)$ & $8.65( \pm 0.8)$ & This work \\
\hline C-D & $15.87( \pm 1.1)$ & $0.41( \pm 0.05)$ & $115( \pm 4)$ & $6.9( \pm 0.5)$ & This work \\
\hline C-E & $24.8( \pm 2.5)$ & $0.3( \pm 0.01)$ & $74( \pm 4)$ & $11.3( \pm 0.5)$ & This work \\
\hline G5 & $16.4( \pm 1.9)$ & $0.4( \pm 0.05)$ & $111( \pm 6)$ & $2.3( \pm 0.2)$ & This work \\
\hline G10 & $20.1( \pm 1.7)$ & $0.4( \pm 0.03)$ & $125( \pm 10)$ & $1.8( \pm 0.2)$ & This work \\
\hline Surface modified CNT & 8 & 0.30 & 72 & 0.14 & 3 \\
\hline
\end{tabular}

$0.25 \mathrm{~V}\left(0.5 \mathrm{~mA} \mathrm{~cm}^{-2}\right),{ }^{58-60} 0.265 \mathrm{~V}$ under acidic conditions and $0.337 \mathrm{~V}$ under basic conditions with Co nanoparticles embedded in N-doped carbon, ${ }^{61}$ and $0.325 \mathrm{~V}\left(10 \mathrm{~mA} \mathrm{~cm}{ }^{-2}\right)$ for the $\mathrm{IrO}_{x}$ catalyst. ${ }^{\mathbf{1 0}}$ The current density generated with the majority of the OER catalysts is usually low except a few such as $\sim 60 \mathrm{~mA} \mathrm{~cm}^{-2}$ for Ni-Co bimetallic alloys, ${ }^{62} 180 \mathrm{~mA} \mathrm{~cm}^{-2}$ with NiFe layered double hydroxide nanoparticles, ${ }^{60}$ and $500 \mathrm{~mA}$ $\mathrm{cm}^{-2}$ at $\eta=0.36 \mathrm{~V}$ for mesoporous $\mathrm{Ni}_{60} \mathrm{Fe}_{30} \mathrm{Mn}_{10}$ based films. ${ }^{63}$ The current density of $\mathrm{C} 5$ is similar to that of the reported metal free $\mathrm{N}$-doped catalysts at comparable potential values. ${ }^{3,7,8}$ The superlative performance of $\mathrm{C} 5$ in a verified electrochemical setup (Table S3 and Fig. S11 $\dagger$ ) $^{64}$ intrigued its viability test under more physiological $\mathrm{pH}$ conditions. From the $\mathrm{pH}$ dependent cyclic voltammogram (CV) measurements it was observed that decreasing the alkalinity of the solution to $\mathrm{pH} 9$ reduces the current density to $11.2( \pm 1) \mathrm{mA} \mathrm{cm} \mathrm{cm}^{-2}$ and the overpotential at $10 \mathrm{~mA} \mathrm{~cm}^{-2}$ increases to $0.45( \pm 0.09) \mathrm{V}$ at $10 \mathrm{~mA} \mathrm{~cm}^{-2}$ (Fig. 2b). At $\mathrm{pH} 7$, the current density drops to $2.5 \mathrm{~mA} \mathrm{~cm}^{-2}$ and the overpotential changes to $0.39( \pm 0.07) \mathrm{V}$ at $1.1 \mathrm{~mA} \mathrm{~cm}^{-2}$ which is however more than that of the recently reported $\mathrm{Ni}$ (II) complex with one of the lowest overpotentials of $\sim 0.17 \mathrm{~V}$ corresponding to $1.1 \mathrm{~mA} \mathrm{~cm}^{-2} .{ }^{17}$ The reduction of current density at $\mathrm{pH}$ below 14 is due to the lower abundance of singly occupied molecular orbitals in C-dots which decreases their ability to act as an electron donor/acceptor such that limited charge transfer is possible. ${ }^{65}$ This is validated from the EPR spectra (Fig. S12†) of C5 which show that its ground state paramagnetic signal at $g=$ 1.99 is much more prominent at $\mathrm{pH} 14$ than at $\mathrm{pH} 7$.

3.2.2 OER activities of C-dots synthesized over longer durations of the microwave reaction. When the microwave reaction time was increased beyond $5 \mathrm{~min}$, the extent of the conversion of trapped 5-HMF to polyaromatic species also increases. From 10 to $30 \mathrm{~min}$ of the microwave reaction, the diameter of the C-dots increases from $3.5 \mathrm{~nm}$ for $\mathrm{C} 10$ to $3.8 \mathrm{~nm}$ for C30 (Fig. 3a and b). As compared to C5, the current density drops by $13 \%$ to $29.2( \pm 1.5) \mathrm{mA} \mathrm{cm} \mathrm{cm}^{-2}$ for $\mathrm{C} 10$ which even
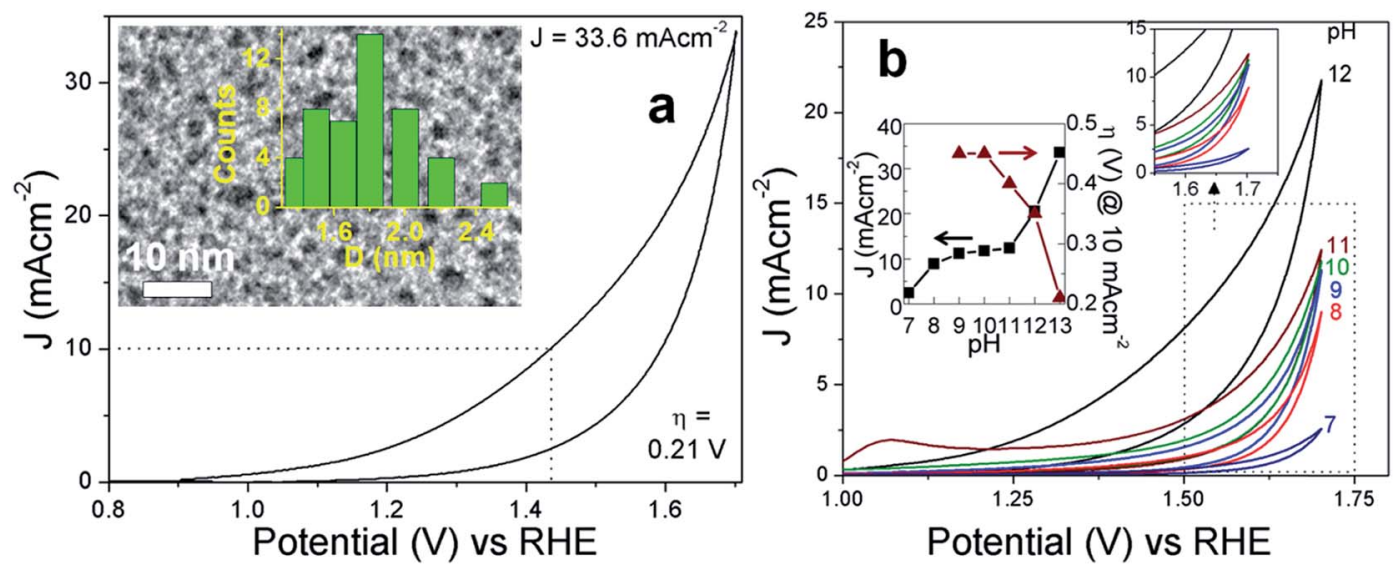

Fig. 2 (a) $\mathrm{CV}$ of $\mathrm{C} 5$ at $\mathrm{pH}$ 14. The inset shows the TEM image of $\mathrm{C} 5$ with the diameter histogram. (b) $\mathrm{pH}$ dependent $\mathrm{CV}$ s of $\mathrm{C} 5$. The inset shows the variation of $\mathrm{J}$ and $\eta$ with $\mathrm{pH}$. 

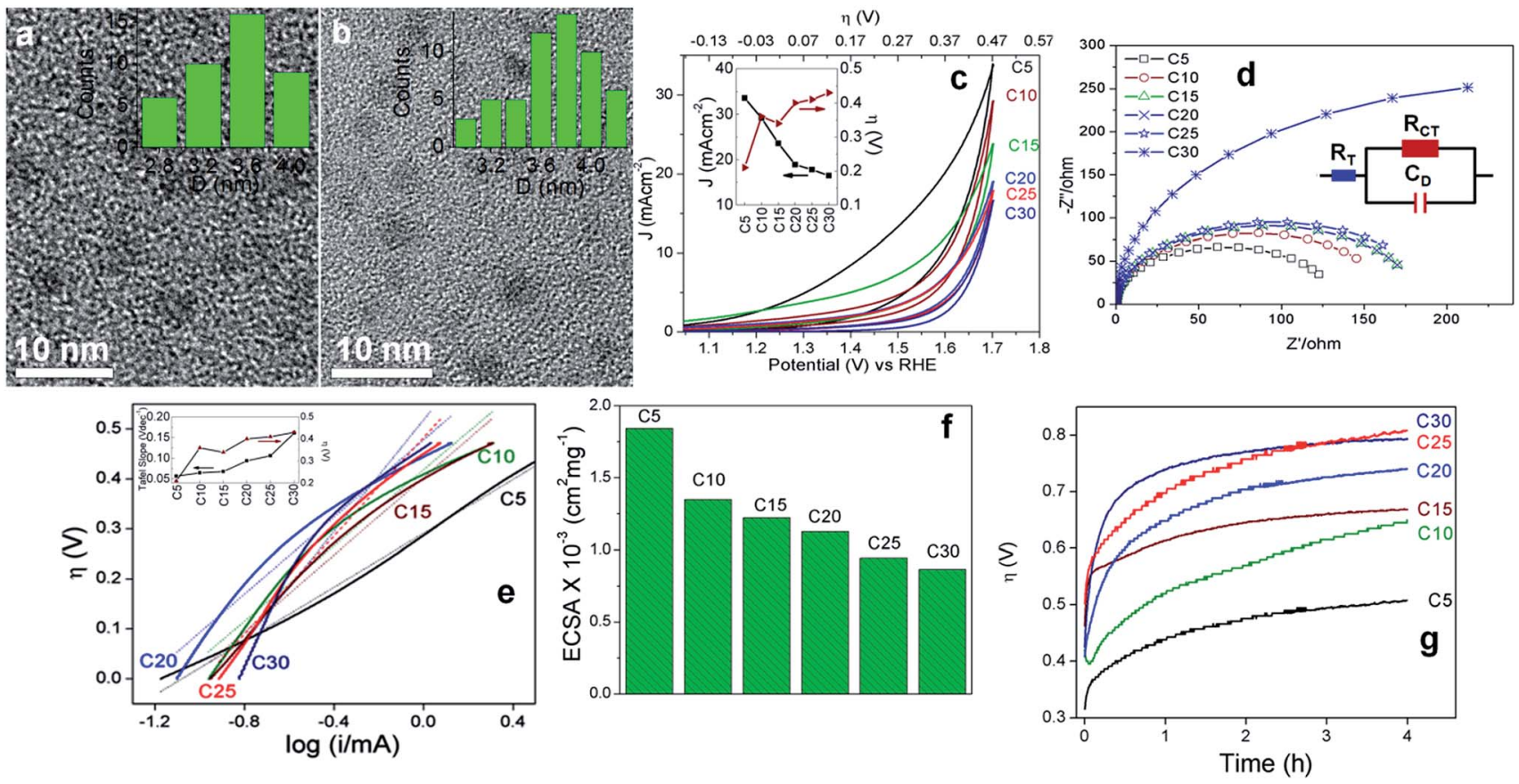

Fig. 3 TEM images of (a) $\mathrm{C} 10$ and (b) C30. The insets show the diameter histogram. (c) CVs at pH 14. The inset shows the variation of $J$ and $\eta$. (d) Nyquist plots. The inset shows the analogous equivalent circuit. (e) Tafel slopes. The inset shows the variation of the Tafel slope and $\eta$. (f) ECSA in $\mathrm{cm}^{2} \mathrm{mg}^{-1}$ and $(\mathrm{g})$ chronopotentiometric curves.

reduces to $16.3( \pm 1.4) \mathrm{mA} \mathrm{cm}^{-2}$ for $\mathrm{C} 30$ (Fig. 3c). The overpotential increases to $0.43( \pm 0.05) \mathrm{V}$ for $\mathrm{C} 30$, which is higher than that of reported benchmark catalysts. The OER activities were repeated 5 times and the standard deviations are tabulated in Table 1. The linear sweep voltammetry (LSV) plots (Fig. S13†) reflect the parameters obtained from the CV plots. To understand the benefits of microwave irradiation, the combination of sucrose, oxalic acid and PVP was refluxed at $100{ }^{\circ} \mathrm{C}$ and C-dots were obtained after $2 \mathrm{~h}$. The refluxed C-dots however did not give any OER activity at pH 14. PVP plays the role of a capping agent and limits the growth of the carbogenic particles to generate 'small' dots as the final product. When PVP was not used, carbonaceous precipitation was observed instead of formation of C-dots, and this carbonaceous product also did not show any OER activity.

The investigation of faradaic resistance was performed by electrochemical impedance spectroscopy which gives an insight into the OER kinetics at an overpotential of $0.3 \mathrm{~V}$. The electrochemical interface is provided by the equivalent circuit shown in Fig. 3d (inset). ${ }^{66}$ Fig. 3d shows the Nyquist plots where C5 exhibits the least resistance; the total Ohmic resistance of the cell $\left(R_{\mathrm{T}}\right)$ and the charge-transfer resistance $\left(R_{\mathrm{CT}}\right)$ being 10 and $130 \mathrm{ohm}$, respectively, indicate the highest charge transfer between electrodes and oxidized/reduced species in accordance with the CV and LSV results. C10 has an $R_{\mathrm{CT}}$ of $155 \mathrm{ohm}, 1.2$ times more than that of C5. $R_{\mathrm{CT}}$ is $280,340,465$ and $538 \mathrm{ohm}$ for C15, C20, C25 and C30, respectively. Likewise, $R_{\mathrm{T}}$ for C10, C15, C20, C25 and C30 is 13, 27, 29, 29 and $53 \mathrm{ohm}$, respectively. The high resistance in the Nyquist plots reflects the poor electrical conductivity of the C-dots which is largely due to the presence of a significant fraction of amorphous elemental carbon, 5-HMF and furan derivatives. However, this disadvantage is overcome by the ability of the trapped anti-oxidant to readily scavenge the intermediate radicals and the presence of keto-groups acting as the catalytic sites.

Fig. 3e represents the Tafel plots of $\mathrm{C} 5-\mathrm{C} 30$ and the Tafel slopes obtained from linear fitting of the plots are tabulated in Table 1 . The linearity of the Tafel plots is maintained in the overpotential range of $0.2-0.4 \mathrm{~V}$, above and below which the plots depart from linearity. C5 shows linearity over the longest overpotential range, showing its relatively higher electrokinetic activity. The Tafel slope obtained for C5 is $68( \pm 4) \mathrm{mV} \mathrm{dec}^{-1}$, which is less than that of surface-oxidized MWCNTs. ${ }^{3}$ The Tafel slope is 1.3 and 1.8 times higher in $\mathrm{C} 10$ and C30, respectively. The electrochemically active surface area (ECSA) was measured as the slope of the curve obtained by plotting the charging current density differences of anodic and cathodic sweeps at different scan rates versus the corresponding scan rates. The equation used for this calculation is: double layer capacitance $\left(C_{\mathrm{DL}}\right)=V_{\mathrm{s}} / I_{\mathrm{c}}$ where $V_{\mathrm{s}}$ is the scan rate and $I_{\mathrm{c}}$ is charging current density differences of anodic and cathodic sweeps. For every C-dot, $I_{\mathrm{c}}$ was recorded at four different scan rates, namely 50 , 100,150 and $200 \mathrm{mV} \mathrm{s}^{-1}$. The detailed $C_{\mathrm{DL}}$ obtained with corresponding scan rates is given in Table S4. $\dagger$ As shown in Fig. $3 \mathrm{f}$ and Table 1, C5 and C10 have the highest ECSA indicating the presence of a large number of catalytically active sites. The ECSA accounts for both the surface and the core volume in the C-dots available for charge transfer between the electrode surface and the reactants. It is observed that the ECSA of C5 $\left(17.5 \mathrm{~cm}^{2}\right)$ is slightly less than that of one of the best performing 
conventional $\mathrm{IrO}_{x},{ }^{10}$ and comparable to that of the $\mathrm{N}$ doped carbon catalyst. ${ }^{7}$ The C-dot catalyzed bulk electrolysis was tested by chronopotentiometry maintaining the current density constant at $10 \mathrm{~mA} \mathrm{~cm}^{-2}$ for $4 \mathrm{~h}$ (Fig. $3 \mathrm{~g}$ ). For all the C-dots, the overpotential increases with time since the long term stability of metal oxide catalysts is unexpected for the C-dots. ${ }^{10} \mathrm{C} 5$ however demonstrated the best performance. In $\mathrm{C} 5$, an initial hike of overpotential to $0.35 \mathrm{~V}$ within $10 \mathrm{~min}$ is followed by a slow rise to $0.5 \mathrm{~V}$ after $4 \mathrm{~h}$. Similarly, C10 shows an initial rise from 0.36 to $0.43 \mathrm{~V}$ within $10 \mathrm{~min}$ and a slow increase to $0.64 \mathrm{~V}$ after $4 \mathrm{~h}$. The sudden drop in activity within $10 \mathrm{~min}$ suggests the conversion of trapped 5-HMF into the furan derivatives (vide infra Section 3.3). Lesser the concentration of trapped 5-HMF greater is its rate of consumption, decreasing the OER activity over time. Since the initial overpotential value could not be stabilized over time, the faradaic efficiency is expectedly low for the C-dots. The above trends are reflected from the chronoamperometric studies performed with controlled electrolysis at $1.53 \mathrm{~V}$ in $1 \mathrm{M} \mathrm{KOH}$ for $4 \mathrm{~h}$ (Fig. S14†). For C5, after an initial drop in current density by $3.8 \mathrm{~mA} \mathrm{~cm}{ }^{-2}$ within $10 \mathrm{~min}$, it stabilizes over $4 \mathrm{~h}$. Rest of the C-dots also show a constant drop in current density with increased time. Up to $4 \mathrm{~h}, \mathrm{C} 10, \mathrm{C} 15, \mathrm{C} 20$, C25 and C30 demonstrate a steady current density of 3.1, 2.3, 2, 1 and $0.2 \mathrm{~mA} \mathrm{~cm}^{-2}$, respectively. The faster attenuation in the chronoamperometric plots of Fig. S14 $\uparrow$ as compared to Fig. $3 \mathrm{~g}$ is due to faster consumption of 5-HMF at a constant higher potential.

To verify the oxygen evolution, $\mathrm{O}_{2}$ formation in the solution phase was measured over time during electrocatalysis with the aid of a Clark type oxygen electrode (YSI, Inc.) (Fig. S15†). The electrolyte solution was degassed with nitrogen and the experiment was performed in a gas tight cell with a stirred $15 \mathrm{~mL} 1 \mathrm{M}$ $\mathrm{KOH}$ solution at $\mathrm{pH} 14$. Vigorous evolution of the gases was observed during the entire course of the electrochemical reaction. The difference between the dissolved oxygen measured before and after electrocatalysis at a constant voltage of $1.6 \mathrm{~V}$ versus RHE is represented as the dissolved oxygen produced over a span of $50 \mathrm{~min}$ (Table S5 and Fig. S16†). With C5, over a period of $42 \mathrm{~min}$, the dissolved oxygen concentration increased from 100 to $270 \mu \mathrm{m}$ i.e. a rise by $170 \%$. For C10-C30, the corresponding rise is $140-160 \%$. The control experiment without the C-dot catalyst shows that only $37 \mu \mathrm{M} \mathrm{O}_{2}$ is dissolved after $50 \mathrm{~min}$, when water was slowly oxidized by the bare glassy carbon electrode at the same potential and $\mathrm{pH}$. The estimation of dissolved $\mathrm{O}_{2}$ undermines the actual evolved oxygen and the faradaic efficiency based on the dissolved $\mathrm{O}_{2}$ for $\mathrm{C} 5$ at an overpotential of $0.35 \mathrm{~V}$ for $3000 \mathrm{~s}$ is estimated to be $20 \%$. Carbon based materials are usually prone to oxidation and in water medium the dissolved $\mathrm{CO}_{2}$ can form carbonic acid which can lower the solution $\mathrm{pH}$. The probability of such an event was tested by measuring the $\mathrm{pH}$ of the reaction mixture at an interval of $500 \mathrm{~s}$ up to $3000 \mathrm{~s}$ at a stretch (Fig. S17†). The constant $\mathrm{pH}$ of every reaction mixture over $3000 \mathrm{~s}$ excludes the possibility of the formation of $\mathrm{CO}_{2}$.

3.2.3 OER activities of C-dots synthesized from other precursors. The diameters of C-A to C-E are in between 2.5 and $4.3 \mathrm{~nm}$ whereas those of G5 and G10 are 5.5 and $4.2 \mathrm{~nm}$, respectively (Fig. 4a-d). The OER performance of C-E matches closely to that of the C10 catalyst (Table 1). The maximum current density and overpotential at $10 \mathrm{~mA} \mathrm{~cm}{ }^{-2}$ for C-A and C-B are similar to those of C20 (Fig. 4e). C-C and C-D demonstrate relatively inferior OER activity similar to C25 and C30. The OER performance of G5 and G10 closely matches that of C-D and C-B, respectively. The OER activity of the C-dots and G-dots is strictly governed by their chemical composition which depends on the synthetic precursors and methods. In the absence of $5-\mathrm{HMF}$, the furan derivatives with $\mathrm{C}=\mathrm{O}$ groups alter the electronic environment of the neighbouring carbon atoms, thus facilitating the adsorption of the radical intermediates favourably leading to oxygen evolution.

From the Tafel plots in Fig. $4 \mathrm{f}$ and the slopes in Table 1, it can be observed that C-A to C-D, G5 and G10 show similar kinetics like C10-C30, C-E being relatively better and close to C5. On average, the ECSA of C-A and C-E is close to that of C10-C20 and that of C-B to C-D is comparable to those of C25 and C30. The graphitized G5 and G10 with a near-perfect arrangement of the $\mathrm{sp}^{2}$ hybridized carbon matrix and relatively lesser topological defects have the least number of catalytic sites and hence the ECSA is the lowest, corroborating the high Tafel slopes. The stability of the three best performing C-dots, C5, C10 and C-E, was also tested by the recyclability tests up to the $300^{\text {th }}$ cycle (Fig. 4g). It was observed that the catalytic performance decreases after each batch of 100 cycles, although C5 shows relatively better performance. Post 100 cycles, C5, C10 and C-E demonstrate current densities of 30,25 and $16 \mathrm{~mA}$ $\mathrm{cm}^{-2}$ and an overpotential of $0.25,0.38$ and $0.35 \mathrm{~V}$, respectively at $10 \mathrm{~mA} \mathrm{~cm}{ }^{-2}$. Post 200 cycles, C5 and C10 yield current densities of 26 and $20 \mathrm{~mA} \mathrm{~cm}^{-2}$ and an overpotential of 0.28 and $0.39 \mathrm{~V}$, respectively at $10 \mathrm{~mA} \mathrm{~cm}{ }^{-2}$. Even after 300 irreversible CV cycles, C5 has an overpotential of $0.31 \mathrm{~V}$, whereas that of C10 is $0.42 \mathrm{~V}$ at $10 \mathrm{~mA} \mathrm{~cm}^{-2}$. Although it is a non-metal catalyst, the OER activity of C5 is exceptional, whereas that of the other C-dots is pretty decent, as compared to the reports available to date.

\subsection{OER mechanism}

Since trapping of the highest concentrations of 5-HMF shows quite unprecedented OER activities, the actual contribution of 5-HMF was tested by employing the molecule alone as a catalyst for water oxidation. $0.001 \mathrm{~g}$ of commercial 5-HMF was mixed with $250 \mu \mathrm{L}$ distilled water, $250 \mu \mathrm{L}$ of ethanol and $25 \mu \mathrm{L}$ of $5 \%$ aqueous Nafion solution. $5 \mu \mathrm{L}$ of the resulting suspension was carefully drop cast onto the surface of the GC disk followed by vacuum drying for $24 \mathrm{~h}$. Under similar conditions to those of the C-dots, 5-HMF shows decent performance with an overpotential of $0.45 \mathrm{~V}$ at $10 \mathrm{~mA} \mathrm{~cm}{ }^{-2}$ and the maximum achieved current density is $14 \mathrm{~mA} \mathrm{~cm}{ }^{-2}$ (Fig. S19†). This again highlights the utility of accommodating 5-HMF in the C-dots. This electrochemical activity of 5-HMF is unlikely due to self-electrooxidation since the electro-oxidation peak for 5-HMF and related compounds appears at lower voltage $(0.8-1.2 \mathrm{~V}$ versus RHE) after several voltammetric cycles and no such peak was observed in the present case. ${ }^{67,68}$ Also, the OER onset potential 

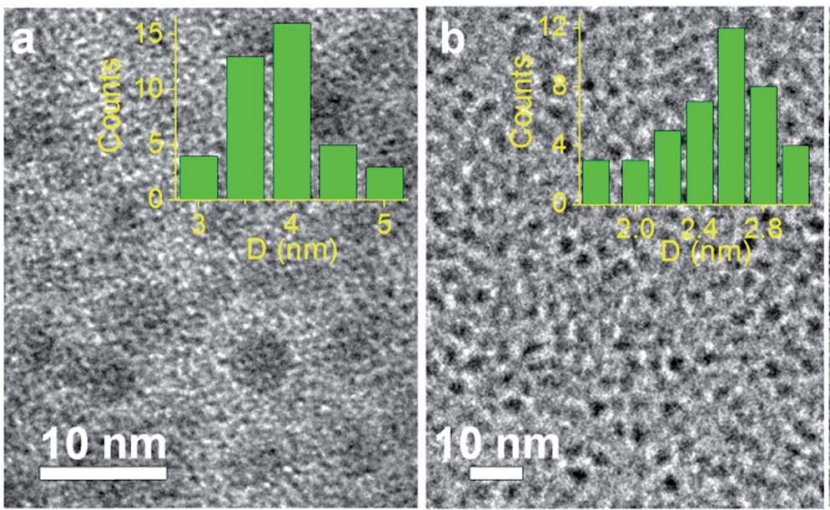

$\eta(\mathrm{V})$

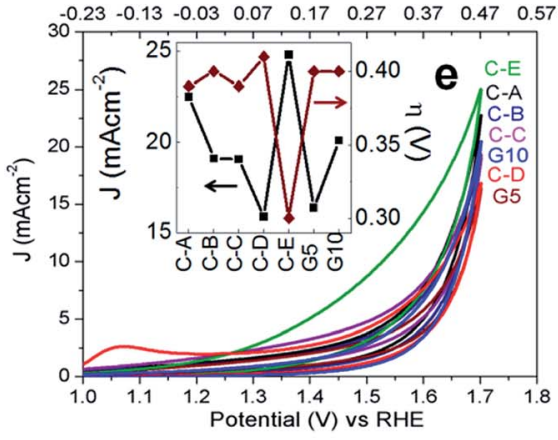

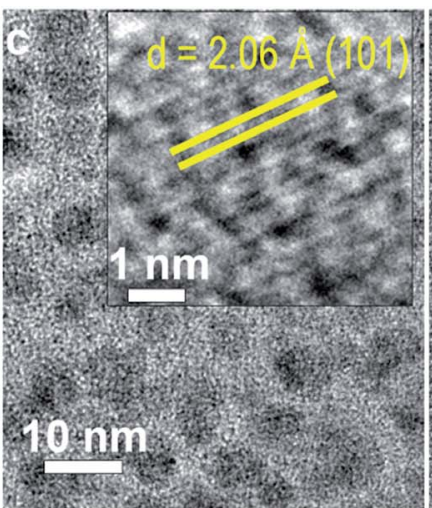
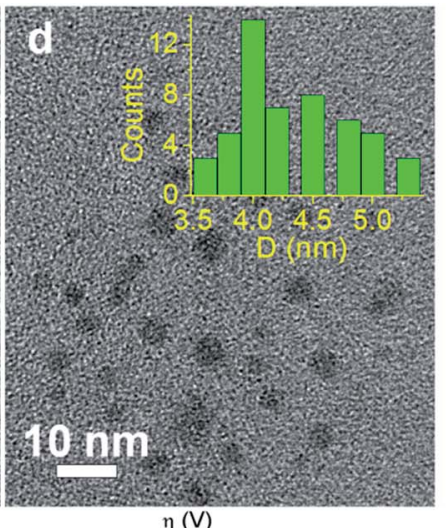
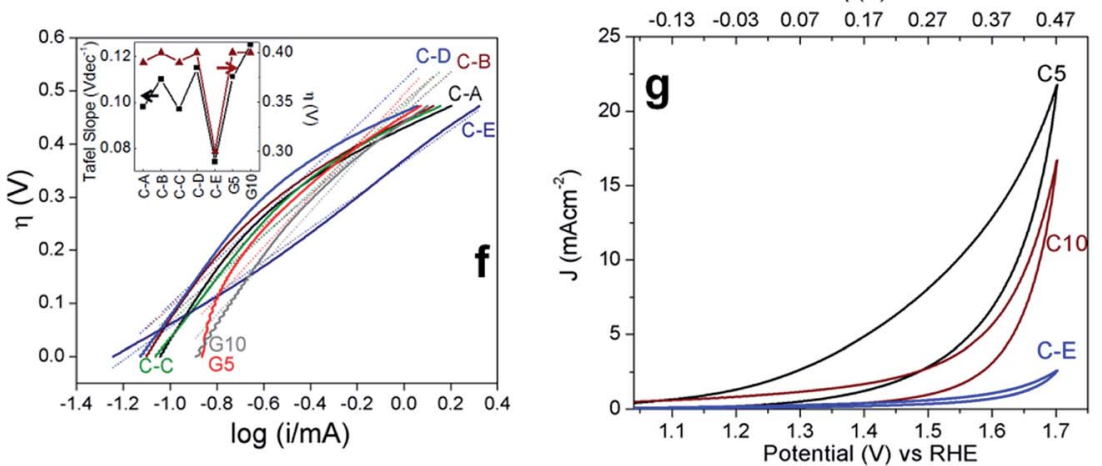

Fig. 4 TEM images of (a) C-B, (b) C-E, (c) G5 and (d) G10. The inset in (c) shows a single G-dot. (e) CVs of C-A-C-E, G5 and G10 at pH 14 . The inset shows the variation of $\mathrm{J}$ and $\eta$. (f) Tafel slopes. The inset shows the variation of the Tafel slope and $\eta$. (g) $\mathrm{CVs}$ at pH 14 after 300 cycles.

for all the C-dots is found to be in the range of 0.96-1.0 V versus RHE, close to the thermodynamic potential of $1.23 \mathrm{~V}$ (Fig. S18 $\dagger$ ). Therefore in the present potential range of study up to $1.7 \mathrm{~V}$ versus RHE, the organic molecules are not electro-oxidized and electrochemical side reactions rarely occur. In the C-dots and G-dots without any anti-oxidant, the carbonyl bands and the topological defects are sufficient to catalyze the forward reactions towards $\mathrm{O}_{2}$ evolution. Our results are in agreement with the previous reports, ${ }^{3,57}$ since irrespective of the presence of any anti-oxidant, all the C-dots and G-dots demonstrate superior OER activity as compared to the well known homogeneous and heterogeneous catalysts. Also, the extremely low QY indicates that the C-dots and G-dots are probably not N-doped since high QY is generally associated with N/S doped C-dots. ${ }^{69}$ The nitrogen content measured by elemental analyses (Table $\mathrm{S} 6$ and Fig. S20 $\dagger$ ) does not match with the trend of OER activity of different C-dots and G-dots. The slightest N-doping is due to the use of precursors such as PVP, ethylenediamine, CTAB and ethanolamine.

In alkaline medium, the sequential oxidation reactions are: $2 \mathrm{H}_{2} \mathrm{O} \rightarrow \mathrm{H}_{2} \mathrm{O}+{ }^{\circ} \mathrm{OH}($ ads $)+\mathrm{H}^{+}+\mathrm{e}^{-}$(step $\left.\mathrm{I}\right) \rightarrow \mathrm{H}_{2} \mathrm{O}+{ }^{\circ} \mathrm{O}($ ads $)+$ $2 \mathrm{H}^{+}+2 \mathrm{e}^{-}$(step II) $\rightarrow{ }^{\circ} \mathrm{OOH}($ ads $)+3 \mathrm{H}^{+}+3 \mathrm{e}^{-}$(step III) $\rightarrow \mathrm{O}_{2}+$ $4 \mathrm{H}^{+}+4 \mathrm{e}^{-}$(step IV). ${ }^{3,4}$ The OER activity is dependent on the adsorption and desorption kinetics of the intermediate radicals at the electropositive sites on the catalyst surface. The $\mathrm{C}=\mathrm{O}$ groups with an electron-withdrawing inductive effect alter the electronic environment of the surrounding carbon atoms for adsorption of the radicals. The advantage of nurturing 5-HMF molecules in the C-dots is two-fold. Firstly, the 5-HMF molecules in close vicinity to these $\mathrm{C}=\mathrm{O}$ groups on the $\mathrm{C}$-dot surface have an exceptional ability to scavenge the radical intermediates leading to faster adsorption kinetics. Secondly, 5-HMF is randomly distributed in the entire "small" volume of the C-dots and due to its strong affinity towards the ${ }^{\circ} \mathrm{OH} /{ }^{\circ} \mathrm{O} /{ }^{\circ} \mathrm{OOH}$ intermediates, enhances their adsorption at the catalytically active sites. The three possible pathways by which 5-HMF can scavenge the radicals are shown in Fig. 5a. The most feasible pathway (A) involves extraction of $\mathrm{H}^{\circ}$ from the $\mathrm{C}_{6}$ position of 5 -HMF, where the allyl radical (I) can be stabilized through conjugation which finally gets oxidized to 2,5-diformylfuran. ${ }^{70}$ The latter with $\mathrm{C}=\mathrm{O}$ and $-\mathrm{CHO}$ groups in turn acts as the active sites for radical adsorption.

As the electrochemical reaction progresses, the 2,5-diformylfuran entities increase in concentration remarkably increasing the active sites of adsorption, at the cost of 5-HMF molecules. The chronopotentiometric curves in Fig. $3 \mathrm{~g}$ suggest that all the 5-HMF molecules are undoubtedly converted to 2,5-diformylfuran within the first $10 \mathrm{~min}$ of bulk electrolysis. Post 10 min of the reaction up to at least $4 \mathrm{~h}$, the OER activity is driven by the standard adsorption and desorption of the radical intermediates to form molecular $\mathrm{O}_{2}$ (Fig. 5b). This clearly explains the steady performance of $\mathrm{C} 5$ containing the highest concentration of 5-HMF, even if this C-dot is electrically nonconducting.

Although the standard OER mechanism can be easily understood once 5-HMF converts to the furan species, the OER 

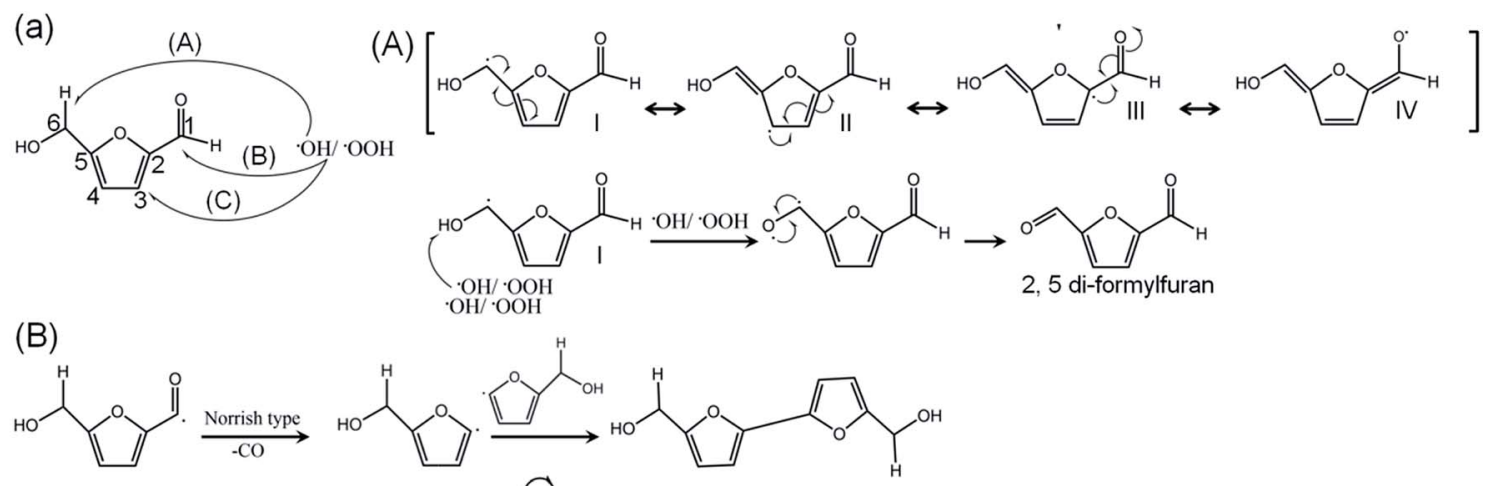

(C)
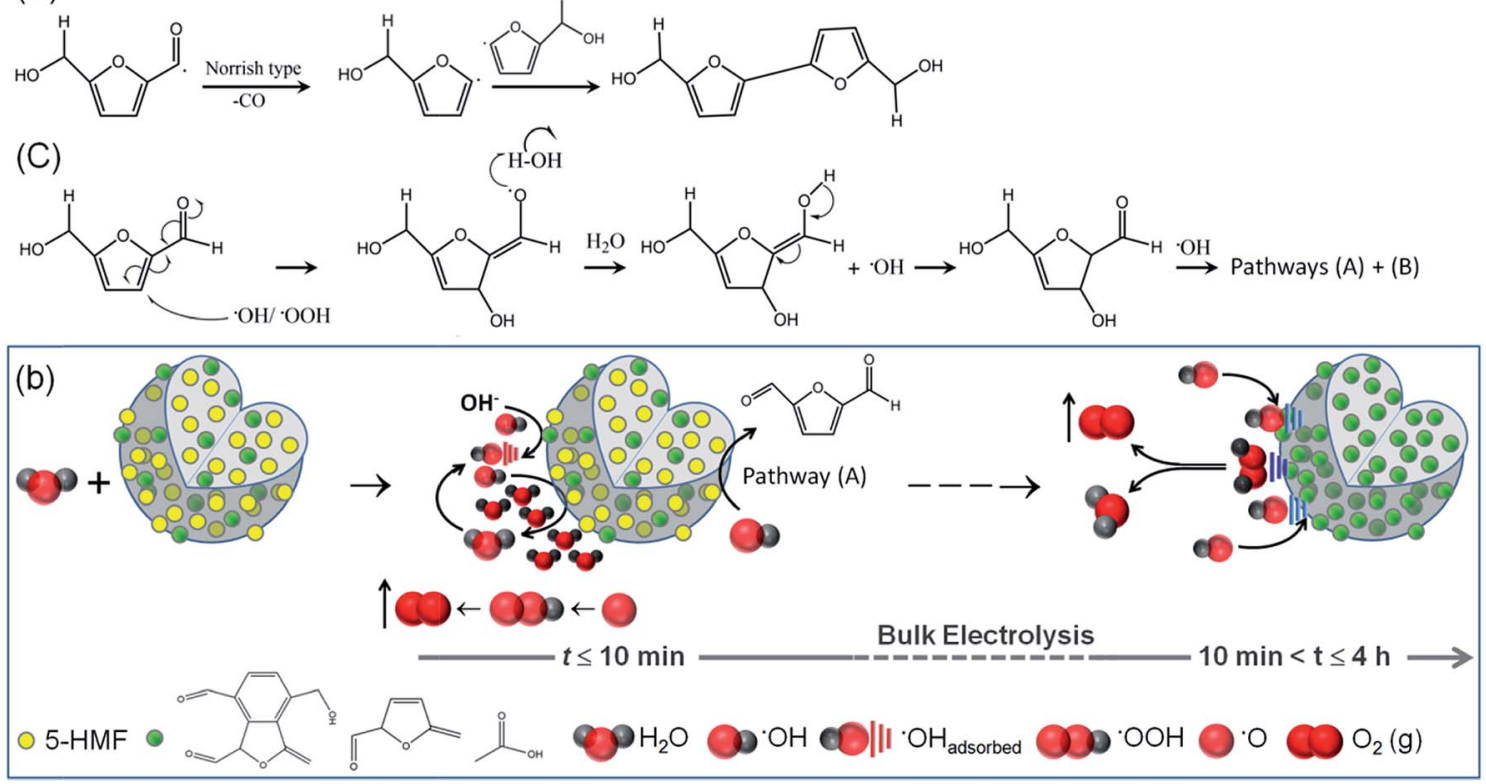

Fig. 5 (a) Mechanistic pathways (A-C) of the extraction of ${ }^{\circ} \mathrm{OH}$ by $5-\mathrm{HMF}$. (b) Schematic representation of bulk electrolysis steps with $\mathrm{C} 5-\mathrm{C} 15 \mathrm{C}$ dot catalysts. At time, $t<10 \mathrm{~min}$, the discharge of $\mathrm{OH}^{-}$ions occurs at the active sites containing $\mathrm{C}=\mathrm{O}$ groups and continued extraction of ${ }^{\circ} \mathrm{OH}$ intermediates by 5-HMF molecules increases the local $\mathrm{H}_{2} \mathrm{O}$ concentration near the active sites leading to vigorous $\mathrm{O}_{2}$ evolution. Simultaneously, the $5-\mathrm{HMF}$ is continuously consumed to yield 2,5-diformylfuran derivatives. When the electrolysis is continued beyond 10 min, the furan derivatives solely dictate the adsorption and desorption of intermediates and govern the OER kinetics, in the absence of 5-HMF.

activity of the C-dots containing 5-HMF within the first $10 \mathrm{~min}$ of bulk electrolysis is intriguing. According to a plausible mechanism, the initial electrolytic discharge of the $\mathrm{OH}^{-}$ions (step I) at the active sites on the surface of the C-dots will allow 5-HMF near the $\mathrm{C}=\mathrm{O}$ groups to extract ${ }^{\circ} \mathrm{OH}$ intermediates and convert them to $\mathrm{H}_{2} \mathrm{O}$ according to the mechanistic pathway (A) in Fig. $5 \mathrm{a}$. When $\mathrm{H}_{2} \mathrm{O}$ concentration increases near the active sites it will shift the equilibrium towards the evolution of $\mathrm{O}_{2}$ in steps I and II according to the Le Châtelier's principle. The kinetics of continued extraction of ${ }^{\circ} \mathrm{OH},{ }^{\circ} \mathrm{O},{ }^{\circ} \mathrm{OOH}$ radicals in steps I-III and regeneration of $\mathrm{H}_{2} \mathrm{O}$ are faster with the presence of 5-HMF in C5-C15 as observed from the lower Tafel slopes (Table 1). With a decrease in the 5-HMF concentration from C5 to $\mathrm{C} 30$, there is a drop in the local $\mathrm{H}_{2} \mathrm{O}$ around the catalytic sites which affects the OER activity. Moreover, the $\mathrm{H}_{2} \mathrm{O}$ molecules formed in situ due to scavenging of ${ }^{\circ} \mathrm{OH} /{ }^{\circ} \mathrm{OOH}$ radicals are assumed to be highly reactive for the processes of ${ }^{\circ} \mathrm{OH}$ migration and rearrangement of the local oxygen environment for the OER at lower overpotentials (Fig. 5b). The pathway (B) of scavenging the radicals (Fig. 5a) is less feasible and involves a Norrish type reaction where ${ }^{\circ} \mathrm{OH} /{ }^{\circ} \mathrm{OOH}$ can extract $\mathrm{H}^{\cdot}$ from $\mathrm{C}_{1}$ and gives a carbonyl radical which consecutively produces the furanyl radical at $\mathrm{C}_{2}$ followed by their fusion to produce a new $\mathrm{C}-\mathrm{C}$ bond. The kinetics of pathway (C) are rather slow and are less likely to occur since the bond dissociation energy of $\mathrm{C}=\mathrm{C}$ is very high $\sim 146$ kcal per mole.

\section{Conclusions}

In summary, we have demonstrated C-dots with a trapped antioxidant, 5-HMF, as a metal-free OER catalyst that can oxidise water at very low overpotential and with high current density. A limited duration of the microwave reaction of sucrose, oxalic acid and PVP precursors could retain the anti-oxidant and increased microwave time converts the anti-oxidant to its furan derivatives. The trapping of 5-HMF inside the C-dots was confirmed by ${ }^{13} \mathrm{C}$ NMR spectroscopy and LC-MS studies. The C-dot with the highest concentration of 5-HMF oxidizes water at a low overpotential of $0.21( \pm 0.03) \mathrm{V}$ generating current density up to $33.6( \pm 2.3) \mathrm{mA} \mathrm{cm}{ }^{-2}$. With $\mathrm{C} 10-\mathrm{C} 30$ electrocatalysts prepared at an increased duration of microwave irradiation, the current densities progressively decrease and the overpotential at $10 \mathrm{~mA} \mathrm{~cm}{ }^{-2}$ increases to $0.34-0.43 \mathrm{~V}$. The C-dots and G-dots prepared from other precursors produce maximum current densities of $15-25 \mathrm{~mA} \mathrm{~cm}{ }^{-2}$ and the overpotentials to reach $10 \mathrm{~mA} \mathrm{~cm}{ }^{-2}$ are $0.39-0.41 \mathrm{~V}$. Within the first $10 \mathrm{~min}$ of bulk 
electrolysis, 5-HMF in $\mathrm{C} 5, \mathrm{C} 10$ and $\mathrm{C} 15$ could extract the ${ }^{\circ} \mathrm{OH} /{ }^{\circ} \mathrm{OOH}$ radicals and can increase the $\mathrm{H}_{2} \mathrm{O}$ concentration around the catalytically active sites such as the topological defects and carbon atoms attached to $\mathrm{C}=\mathrm{O}$ for vigorous $\mathrm{O}_{2}$ evolution. Post $10 \mathrm{~min}, 5-\mathrm{HMF}$ is likely consumed and the resulting furan derivatives act as catalytic sites to drive the OER activity. Therefore, one of the limitations of this approach for designing OER catalysts is the unstable nature of 5-HMF which decomposes to the furan derivatives over the course of continuous electrolysis. Secondly, the electro-kinetics are challenged by the poor electrical conductivity of the C-dots which is due to the presence of amorphous elemental carbon, 5-HMF and furan derivatives. However, this disadvantage is overcome by the ability of the trapped anti-oxidant to readily scavenge the intermediate radicals and the presence of keto-groups acting as the catalytic sites. The 5-HMF molecules could not be trapped in the differently synthesized C-dots from precursors other than sucrose, oxalic acid and PVP. Here the keto groups and topological defects facilitate the OER activity albeit at higher overpotentials compared to the anti-oxidant containing C-dots. Although the stability of 5-HMF is a matter of concern and needs to be addressed, we believe that our approach will open up new avenues in the OER and has the potential to be extended to other anti-oxidants produced from carbohydrates (Table S7 $\dagger$ ). The antioxidants can be impregnated or intercalated within functionalized carbon nanomaterials such as carbon nanotubes and graphene or other well known OER catalysts.

\section{Acknowledgements}

The Department of Science and Technology (DST), Government of India is duly acknowledged for the financial support under grant no. SR/S1/PC-28/2011. AD and SK thank University Grants Commission (UGC) and Council of Scientific and Industrial Research (CSIR), New Delhi, India for their fellowships, respectively. S. B. acknowledges the academic and research funding of IISER Kolkata.

\section{Notes and references}

1 J. K. Hurst, Science, 2010, 328, 315.

2 S. M. Barnett, K. I. Goldberg and J. M. Mayer, Nat. Chem., 2012, 4, 498.

3 X. Lu, W. Yim, B. Suryanto and C. Zhao, J. Am. Chem. Soc., 2015, 137, 2901.

4 H. Dau, C. Limberg, T. Reier, M. Risch, S. Roggan and P. Strasser, ChemCatChem, 2010, 2, 724.

5 F. M. Toma, A. Sartorel, M. Iurlo, M. Carraro, P. Parisse, C. Maccato, S. Rapino, B. R. Gonzalez, H. Amenitsch, T. D. Ros, L. Casalis, A. Goldoni, M. Marcaccio, G. Scorrano, G. Scoles, F. Paolucci, M. Prato and M. Bonchio, Nat. Chem., 2010, 2, 826.

6 J. Yano, J. Kern, K. Sauer, M. J. Latimer, Y. Pushkar, J. Biesiadka, B. Loll, W. Saenger, J. Messinger, A. Zouni and V. K. Yachandra, Science, 2006, 314, 821.

7 Y. Zhao, R. Nakamura, K. Kamiya, S. Nakanishi and K. Hashimoto, Nat. Commun., 2013, 4, 2390.
8 Y. Zheng, Y. Jiao, Y. Zhu, L. H. Li, Y. Han, Y. Chen, A. Du, M. Jaroniec and S. Z. Qiao, Nat. Commun., 2014, 5, 3783.

9 T. Reier, M. Oezaslan and P. Strasser, ACS Catal., 2012, 2, 1756.

10 C. C. L. McCrory, S. Jung, J. C. Peters and T. F. Jaramillo, J. Am. Chem. Soc., 2013, 135, 16977.

11 J. Pfrommer, M. Lublow, A. Azarpira, C. Göbel, M. Lücke, A. Steigert, M. Pogrzeba, P. W. Menezes, A. Fischer, T. Schedel-Niedrig and M. Driess, Angew. Chem., Int. Ed., 2014, 53, 5183.

12 O. Diaz-Morales, T. J. P. Hersbach, D. G. H. Hetterscheid, J. N. H. Reek and M. T. M. Koper, J. Am. Chem. Soc., 2014, 136, 10432.

13 M. Zhang, M.-T. Zhang, C. Hou, Z.-F. Ke and T.-B. Lu, Angew. Chem., Int. Ed., 2014, 53, 13042.

14 S. Pintado, S. Goberna-Ferrón, E. C. Escudero-Adán and J. Galán-Mascarós, J. Am. Chem. Soc., 2013, 135, 13270.

15 J. D. Baran, H. Grönbeck and A. Hellman, J. Am. Chem. Soc., 2014, 136, 1320.

16 Y. Shiraishi, S. Kanazawa, Y. Kofuji, H. Sakamoto, S. Ichikawa, S. Tanaka and T. Hirai, Angew. Chem., Int. Ed., 2014, 53, 13454.

17 M. Zhang, M.-T. Zhang, C. Hou, Z.-F. Ke and T.-B. Lu, Angew. Chem., Int. Ed., 2014, 53, 13042.

18 A. Annamalai, A. G. Kannan, S. Y. Lee, D.-W. Kim, S. H. Choi and J. S. Jang, J. Phys. Chem. C, 2015, 119, 19996.

19 G. Xie, K. Zhang, B. Guo, Q. Liu, L. Fang and J. R. Gong, Adv. Mater., 2013, 25, 3820.

20 N. Zhang, Y. Zhang and Y.-J. Xu, Nanoscale, 2012, 4, 5792.

21 K. Cheng, D. He, T. Peng, H. Lv, M. Pan and S. Mu, Electrochim. Acta, 2014, 132, 356.

22 A. Datta, S. Kapri and S. Bhattacharyya, Green Chem., 2015, 17, 1572.

23 I. V. Lightcap and P. V. Kamat, J. Am. Chem. Soc., 2012, 134, 7109.

24 S. Bhattacharyya, I. Perelshtein, O. Moshe, D. H. Rich and A. Gedanken, Adv. Funct. Mater., 2008, 18, 1641.

25 Z. Bullard, E. C. Girão, J. R. Owens, W. A. Shelton and V. Meunier, Sci. Rep., 2015, 5, 7634.

26 S. Kapri, S. Maiti and S. Bhattacharyya, Carbon, 2016, 100, 223.

27 R. Singhal, Z. Orynbayeva, R. V. K. Sundaram, J. J. Niu, S. Bhattacharyya, E. Vitol, M. Schrlau, E. Papazoglou, G. Friedman and Y. Gogotsi, Nat. Nanotechnol., 2011, 6, 57.

28 R. Singhal, S. Bhattacharyya, Z. Orynbayeva, E. Vitol, G. Friedman and Y. Gogotsi, Nanotechnology, 2010, 21, 015304.

29 V. Pelletier, S. Bhattacharyya, I. Knoke, F. Forohar, M. Bichay and Y. Gogotsi, Adv. Funct. Mater., 2010, 20, 3168.

30 X. Duan, H. Sun, Y. Wang, J. Kang and S. Wang, ACS Catal., 2015, 5, 553.

31 H. Fei, R. Ye, G. Ye, Y. Gong, Z. Peng, X. Fan, E. L. G. Samuel, P. M. Ajayan and J. M. Tour, ACS Nano, 2014, 8, 10387.

32 Y. Gong, H. Fei, X. Zou, W. Zhou, S. Yang, G. Ye, Z. Liu, Z. Peng, J. Lou, R. Vajtai, B. I. Yakobson, J. M. Tour and P. M. Ajayan, Chem. Mater., 2015, 27, 1181. 
33 I.-Y. Jeon, H-J. Choi, S-M. Jung, J-M. Seo, M-J. Kim, L. Dai and J-B. Baek, J. Am. Chem. Soc., 2012, 135, 1386.

34 R. L. Doyle, I. J. Godwin, M. P. Brandon and M. E. G. Lyons, Phys. Chem. Chem. Phys., 2013, 15, 13737.

35 S. Y. Lim, W. Shen and Z. Gao, Chem. Soc. Rev., 2015, 44, 362. 36 M. Zhang, Q. Yao, W. Guan, C. Lu and J. M. Lin, J. Phys. Chem. C, 2014, 118, 10441.

37 Y. Han, H. Huang, H. Zhang, Y. Liu, X. Han, R. Liu, H. Li and Z. Kang, ACS Catal., 2014, 4, 781.

38 D. Qu, M. Zheng, P. Du, Y. Zhou, L. Zhang, D. Li, H. Tan, Z. Zhao, Z. Xie and Z. Sun, Nanoscale, 2013, 5, 12272.

39 T. F. Yeh, C. Y. Teng, S. J. Chen and H. Teng, Adv. Mater., 2014, 26, 3297.

40 H. He, X. Wang, Z. Feng, T. Cheng, X. Sun, Y. Sun, Y. Xia, S. Wang, J. Wang and X. Zhang, J. Mater. Chem. B, 2015, 3, 4786.

41 M. Xu, S. Xu, Z. Yang, M. Shu, G. He, D. Huang, L. Zhang, L. Li, D. Cuia and Y. Zhang, Nanoscale, 2015, 7, 15915.

42 H. Zhu, X. Wang, Y. Li, Z. Wang, F. Yang and X. Yang, Chem. Commun., 2009, 5118.

43 S. Mitra, S. Chandra, P. Patra, P. Pramanik and A. Goswami, J. Mater. Chem., 2011, 21, 17638.

44 A. Jaiswal, S. S. Ghosh and A. Chattopadhyay, Chem. Commun., 2012, 48, 407.

45 X. Zhai, P. Zhang, C. Liu, T. Bai, W. Li, L. Dai and W. Liu, Chem. Commun., 2012, 48, 7955.

46 H. Li, X. He, Y. Liu, H. Huang, S. Lian, S.-T. Lee and Z. Kang, Carbon, 2011, 49, 605.

47 M. J. Krysmann, A. Kelarakis, P. Dallas and E. P. Giannelis, J. Am. Chem. Soc., 2012, 134, 747.

48 Y. Wang and A. Hu, J. Mater. Chem. C, 2014, 2, 6921.

49 T. Nakagawa, N. S. Bjorge and R. W. Murray, J. Am. Chem. Soc., 2009, 131, 15578.

50 S. D. Tilley, M. Cornuz, K. Sivula and M. Grätzel, Angew. Chem., Int. Ed., 2010, 49, 6405.

51 X. Liu, S. Cui, Z. Sun and P. Du, Electrochim. Acta, 2015, 160, 202.
52 N. Murai, M. Yonaga and K. Tanaka, Org. Lett., 2012, 14, 1278.

53 B. De and N. Karak, RSC Adv., 2013, 3, 8286.

54 M. M. Titirici, M. Antonietti and N. Baccile, Green Chem., 2008, 10, 1204.

55 H. Pawara and A. Lali, RSC Adv., 2014, 4, 26714.

56 Y. Yang, H. Fei, G. Ruan, C. Xiang and J. M. Tour, ACS Nano, 2014, 8, 9518.

57 Y. X. Li, Y. Li, Z. J. Qian, M. M. Kim and S. K. Kim, J. Microbiol. Biotechnol., 2009, 19, 1319.

58 M.-M. Titirici and M. Antonietti, Chem. Soc. Rev., 2010, 39, 103.

59 N. L. Weinberg and H. R. Weinberg, Chem. Rev., 1968, 68, 449.

60 R. Chen, G. Sun, C. Yang, L. Zhang, J. Miao, H. Tao, H. Yang, J. Chen, P. Chen and B. Liu, Nanoscale Horiz., 2016, 1, 156.

61 H. Fei, Y. Yang, Z. Peng, G. Ruan, Q. Zhong, L. Li, E. L. G. Samuel and J. M. Tour, ACS Appl. Mater. Interfaces, 2015, 7, 8083.

62 A. A. Baradii, K. B. Kokoh, H. Huser, C. Lamy and J.-M. Léger, Electrochim. Acta, 1999, 44, 2779.

63 E. Detsi, J. B. Cook, B. K. Lesel, C. L. Turner, Y.-L. Liang, S. Robbennolt and S. H. Tolbert, Energy Environ. Sci., 2016, 9, 540 .

64 G. Grabowski, J. Lewkowski and R. Skowroński, Electrochim. Acta, 1991, 36, 1995.

65 L. Zhao, F. Di, D. Wang, L.-H. Guo, Y. Yang, B. Wan and H. Zhang, Nanoscale, 2013, 5, 2655.

66 N. Baccile, G. Laurent, F. Babonneau, F. Fayon, M. M. Titirici and M. Antonietti, J. Phys. Chem. C, 2009, 113, 9644.

67 G. R. Akien, L. Qi and I. T. Horváth, Chem. Commun., 2012, 48, 5850 .

68 S. Jiang, Z. Li, H. Wang, Y. Wang, L. Menga and S. Song, Nanoscale, 2014, 6, 14262.

69 O. Kargbo, Y. Jin and S.-N. Ding, Curr. Anal. Chem., 2015, 11, 4.

70 D. Könning, W. Hiller and M. Christmann, Org. Lett., 2013, 14, 624 . 